\title{
Cultural Diversity and Transformation in the Appraisal of Leadership Characteristics
}

\author{
Pia Anderson \\ American University of Sharjah
}

\begin{abstract}
Qualities that define a leader are often indeterminate and difficult to measure. Leadership traits vary by cultural group and gender and the appraisal of leadership traits is subject to diverse fluctuations in society such as economics and technology. Leadership characteristics are also defined by what kind of leader is deemed appropriate for a specific time period, or for a type of authority - a political leader versus a business leader, for example. This study surveys three different cultural groups to consider what qualities, behaviors and values leaders are judged by and examines what are perceived to be the best methods of leadership in three different cultures.
\end{abstract}

Key words: Culture; Gender; Governance; Ideology; Technology 